\title{
Experimental Organism Benign Mixed Sex Cord Stromal Tumor
}

National Cancer Institute

\section{Source}

National Cancer Institute. Experimental Organism Benign Mixed Sex Cord Stromal

Tumor. NCI Thesaurus. Code C124614.

A sex cord-stromal tumor that arises from the testis or ovary and does not metastasize. 